\title{
The Effect of Cabbage Leaf Treatment in Alleviating Breast Engorgement in Postpartum Mother
}

\author{
* $1^{\text {st }}$ Nidatul Khofiyah \\ Faculty of Health Sciences \\ Universitas Aisyiyah Yogyakarta \\ Yogyakarta, Indonesia \\ nidatulkhofiyah@unisayogya.ac.id
}

\author{
$2^{\text {nd }}$ Siwi Dwi Febriyanti \\ Faculty of Health Sciences \\ Universitas Aisyiyah Yogyakarta \\ Yogyakarta, Indonesia \\ line 5: email address
}

\begin{abstract}
Breast engorgement takes place because breast milk is not implanted adequately. In consequence, the rest of the milk is collected in the ductal system triggering engorgement. If the breast engorgement is not resolved, mastitis and breast abscess will occur. This study aims to determine the effect of cabbage leaf treatment in alleviating breast engorgement in postpartum mothers. This research conducted a pre-experiment with one group pretest-posttest design method. The samples were selected with accidental sampling and analyzed with paired t-tests. The instrument of this study was a six-point engorgement scale (SPES). The statistical test showed that there was an effect of giving cabbage leaf compresses to relieve breast swelling in postpartum mothers with $p=0,000$. The results of this study were expected to be a reference in treating breast engorgement by handling cabbage leaf treatment as non-pharmacological therapy.
\end{abstract}

Keywords — cabbage leaf treatment, engorgement, breast swelling, non-pharmacological therapy

\section{INTRODUCTION}

Breastfeeding is a way to provide ideal food for baby growth and development. Anti-infectious substances contained in breast milk help protect babies from disease. However, breastfeeding sometimes cannot run regularly. Many mothers complain about their swelling breast due to the accumulation of breast milk. According to the latest World Health Organization (WHO) data in the United States, the percentage of breastfeeding women who experienced engorgement in 2015 were $66.34 \%$, alternatively, 6,543 of 9,862 postpartum mothers [1].

If the engorgement is not resolved, mastitis and breast abscess will occur. Mastitis is an inflammation or infection of the breast where the symptoms range from hard, flushed, and painful breasts to fever $>380 \mathrm{C}$, while breast abscess is a further complication after mastitis where pus accumulation in the breast [2].

Some factors that can reduce breast engorgement with pharmacological treatment are the consumption of drugs, such as paracetamol, Ibuprofen, and lynoral [3]. By contrast, non-pharmacological treatment ranges from more frequent breastfeeding, warm compresses, pumping milk and massage, and breast care. On top of that, one of the non- pharmacological treatment of breast engorgement is cabbage leaf treatment [4].

Compressing cabbage leaves are proven to reduce swelling in areas of the body that experience swelling. This procedure takes advantage of the body's natural response to substances contained in cabbage that are absorbed by the skin and the cold effect of cabbage, which relieve pain and swelling in the breast. Cabbage is also rich in sulfur content. It is widely believed to reduce breast swelling and inflammation [5].

\section{RESEARCH METHOD}

This study aims to determine the effect of cabbage leaf treatment in alleviating breast engorgement in postpartum mothers. The study was designed with one group pretestposttest. The sample in this study were postpartum mothers who experience breast engorgement. The researchers only limited the respondent to 15 respondents. The sampling technique used in this study was accidental sampling. The research tool used for data collection in this study was a standard instrument by directly evaluating the incidence of engorgement and using an observation sheet containing a six-point engorgement scale (SPES) that had become a standard tool for assessing engorgement. The data were analyzed with a parametric method and a t-test (paired t-test) statistical test.

\section{RESULT}

Table 1 shows that all the ages of the respondents were in a healthy reproductive age. The youngest age was 22 years, and the oldest was 35 years. As regards parity status, from 15 respondents, most of them, 11 people $(73.3 \%)$, were primipara, and 4 people $(26.7 \%)$ were multipara. Concerning education, 9 people $(60 \%)$ were educated, and 6 people were less educated $(40 \%)$. Furthermore, turning to work status, many respondents did not work, 11 people $(73.3 \%)$, and those who worked were 4 people $(26.7 \%)$. 
TABLE I. CHARACTERISTICS OF RESPONDENTS WHO EXPERIENCE BREAST ENGORGEMENT

\begin{tabular}{lcc}
\hline \multicolumn{1}{c}{ Characteristics } & F & Percentage \\
\hline Age of Postpartum Mother & 15 & $100 \%$ \\
$20-35$ & 0 & 0 \\
$36-45$ & & \\
Parity & 11 & $73,3 \%$ \\
Primipara & 4 & $26,7 \%$ \\
Multipara & & \\
Education & 6 & $40 \%$ \\
Low & 9 & $60 \%$ \\
High & & \\
Occupation & 11 & $73,3 \%$ \\
Do not work & 4 & $26,7 \%$ \\
Work & & \\
\hline
\end{tabular}

TABLE II. SCALE OF BREAST SWELLING OF POSTPARTUM MOTHER BEFORE AND AFTER COMPRESSING THE CABBAGE LEAVES

\begin{tabular}{lcccc}
\hline \multicolumn{1}{c}{ Intervention } & Mean & SD & Min- Max & CI (95\%) \\
\hline Pretest & 4,20 & 1,14 & $2-6$ & $3,57-4,83$ \\
Posttest & 2,40 & 0,82 & $1-4$ & $1,94-2,86$
\end{tabular}

Based on table 2 above, it can be seen that the average scale of engorgement in postpartum mothers before (pretest) intervention was 4.20. The minimum scale for measuring engorgement was 2 and the maximum 6 . Moreover, the average engorgement scale in postpartum mothers after (posttest) intervention was 2.40. The minimum score for the measurement of engorgement was 1 and a maximum of 4 .

TABLE III. NORMALITY TEST

\begin{tabular}{lccc}
\hline \multirow{2}{*}{ Intervention } & \multicolumn{3}{c}{ Shapiro-Wilk } \\
\cline { 2 - 4 } & Statistic & Df & Sig. \\
\hline Pretest & 0.936 & 15 & 0.335 \\
Posttest & 0.883 & 15 & 0.052 \\
\hline
\end{tabular}

Based on table 3, the normality test, which used ShapiroWilk, shows the results of the two data groups were normally distributed. Therefore, the paired sample t-test with a significant level of $\mathrm{p}<0.05$ can be used.

TABLE IV. DIFFERENCE IN SCALE REDUCTION IN ENGORGEMENT BEFORE AND AFTER COMPRESSING THE CABBAGE LEAVES

\begin{tabular}{lcccccc}
\hline \multirow{2}{*}{ Variable } & $\begin{array}{c}\text { Mean } \\
\text { difference }\end{array}$ & p-value & SD & \multicolumn{2}{c}{ CI; 95\% } \\
\cline { 5 - 7 } & 1,8 & 0,000 & 0,775 & 1,371 & 2,229 \\
Scale of & Engorgement & & & &
\end{tabular}

Paired sample t-test statistical results from table 4 obtained p-value of $0,000(\mathrm{p}<0.05)$. That is, there was a significant difference in the average scale of engorgement in postpartum mothers before and after the cabbage leaf compress intervention. Statistically, it implies that cabbage leaf compress was proven to reduce the scale of engorgement in postpartum mothers. In that situation, the scale of postpartum breast engorgement before compressed with cabbage leaves was larger than after compressed with cabbage leaves.

\section{DISCUSSION}

The characteristics of respondents were on healthy reproductive age, the youngest was 22 years old, and the oldest was 35 years old. The mother's age affects the ability and self-readiness in passing through the puerperium and breastfeeding. Mothers who are 40 years old are different in passing postpartum and breastfeeding, compared to mothers who are 18 years old. In this study, the researchers assumed that age 20-30 years was physically and emotionally mature. Consequently, at this age, it is more straightforward to receive and digest information obtained or given.

Concerning parity, most of the respondents were primipara, 11 people $(73.3 \%)$, and multipara, 4 people $(26.7 \%)$. In this study, the researchers assumed that the mother who first gave birth did not have experience in breast care. Consequently, she has no clue related to milk production. On the other hand, a mother who has given birth has adequate knowledge because her previous experience is very much related to the learning process of the second and subsequent children. This is in line with Salgaonkar, breast engorgement is one of the most common minor discomforts of the women after delivery, especially primipara [6].

Regarding the education of the respondents, the majority were highly educated, with 9 people $(60 \%)$, while those with low education were 6 people $(40 \%)$. The higher the level of knowledge of breastfeeding mothers, the higher the knowledge and awareness of breastfeeding mothers to improve and regulate eating patterns when breastfeeding that will affect the smooth production of breast milk. In this study, the researchers assume that the higher a person's education is, the more experience and information they would obtain, implying that the more knowledge that the mother would have.

The results showed that the scale of engorgement in postpartum mothers before (pretest) cabbage leaf compress intervention was 4.20 , or included in heavy breast swelling, the minimum scale measurement results for breast swelling scale was 2 and maximum 6 . Furthermore, the scale of breast swelling in postpartum mothers after (posttest) cabbage leaf compress intervention was 2.40 or included in mild breast swelling, the minimum scale measurement results for breast swelling scale was 1 and maximum 4.

Engorgement often occurs on the third or fourth day because breast milk is not adequately supplemented so that the remaining milk is collected in the ductal system, resulting in swelling and pressure throughout the breast increases. As a result, the breast often feels full, tense, and aches and pains. A decrease typically follows in milk production and a decrease in let-down reflex [7].

As noted by Lim et al. [8], Astuti et al. [9], breast enlargement and pain begin in postpartum, the first to the fourth day, and can continue beyond the fourth day in women who are not breastfeeding. Swelling occurs in 21$52 \%$ of women, while severe swelling is experienced by $1-$ $44 \%$. Pain is being reported experienced by $29-68 \%$ of 
women, and $10-33 \%$ of women experience severe pain for up to 14 days, half of them require analgesia to relieve breast pain.

The results of the paired sample t-test statistical analysis showed that the average difference in the scale of breast swelling in postpartum mothers before (pretest) and after (posttest) intervention of cabbage leaf compresses was 1,8 . Statistical test results obtained $\mathrm{p}$-value $0,000(\mathrm{p}<\alpha 0.05)$, indicating that there were significant differences in the average scale of breast swelling in postpartum mothers before and after the intervention of cabbage leaf compresses. That is, statistically, compressing cabbage leaves was proven to decrease the scale of breast swelling in postpartum mothers, in which the scale of breast swelling in postpartum mothers before compressed with cabbage leaves was significantly higher. The reduction in breast swelling scale after being given a cabbage leaf compress, according to Green, is due to the high sulfur content in cabbage, which is liable to reduce swelling and breast inflammation [5]. Farah (2013) explains that cabbage has antibiotic and antiinflammatory properties because it contains sinigrin (Allylisonthiocyanate), rafine, mustard oil, magnesium, and sulfur that can help widen capillary blood vessels, thereby increasing blood flow to and from the area, and allowing the body to reabsorb the liquid that is blocked in the breast [10].

Cabbage has much nutritional content and also has useful active compounds. One of the active compounds is indol-3carbinol, which is able to prevent and treat cancer. A study shows that consuming three servings or more of vegetable Cruciferae can reduce the risk of prostate cancer, compared to consuming only one serving a week. Even so, consumption of 1-2 servings of vegetables per day has been proven to reduce the risk of breast cancer by $20-40 \%$ due to Sulforafan and Indol compounds contained in cabbage that are anticancer [10].

This is in line with Rohmah et al., finding that in the intervention group (given cabbage leaf compresses), the mean rank of breast swelling in postpartum mothers with engorgement after cold cabbage leaf compress is lower then the mean rank of breast swelling in the control group. The results of data analysis using wilcoxon showed that a cabbage leaf compress can reduce breast swelling [3].

According to the researchers, compress cabbage to treat breast swelling is very economical, natural, and can be found in any area. In addition, the way to use cabbage is very practical and does not interfere with the comfort of the mother, such as breast massage.

This study was in line with a study conducted by Sharma [11] and Robert [12], that shows that cabbage leaf compresses are effective in reducing discomfort in the breast when it is full and swollen. Swelling can occur at any time as in the condition of oversupply of milk when the baby sleeps longer at night. In the morning, the mother will experience breast swelling. In this condition, compressing cabbage leaves on the breast will be very helpful in reducing breast swelling in postpartum mothers [13].

According to Wong et al. [14] and Gagandeep et al. [5], cabbage leaf treatment used on women with breast engorgement does reduce pain and the hardness of the engorged breasts, including increasing the duration of the breastfeeding. The other study shows that cold cabbage leaves can relieve pain and hardness in breast engorgement $(\mathrm{p}=0.016)$, which is recommended for managing breast engorgement in postpartum mothers [15].

\section{CONCLUSION}

In conclusion, there is an effect of compressing cabbage leaf to overcome breast engorgement in postpartum mothers. The research recommends that cabbage leaf compresses be applied to handle breast engorgement during the puerperium.

\section{REFERENCES}

[1] World Health Organization, World Health Statistics 2012. 2012.

[2] A. Maryunani, Asuhan pada ibu dalam masa nifas (postpartum). Jakarta: Trans Info Media, 2014.

[3] M. Rohmah, A. Wulandari, and D. W. Sihotang, "Efektivitas Kompres Daun Kubis (Brassica Oleracea) terhadap Skala Pembengkakan Payudara pada Ibu Post Partum di PMB Endang Kota Kediri,” J. Qual. Women's Heal., 2019, doi: 10.30994/jqwh.v2i2.34.

[4] N. Zuhana, "Perbedaan Efektifitas Daun Kubis Dingin (Brassica Oleracea Var. Capitata) dengan Perawatan Payudara dalam Mengurangi Pembengkakan Payudara (Breast Engorgement), J J. Ilm. Bidan, 2017.

[5] Gagandeep, N. Sagar, Mamta, and J. Kaur, "Efficacy of Cabbage Leaves in Relief of Breast Engorgement among Postnatal Mothers," Int. J. Nurs. Educ., 2013, doi: 10.5958/j.0974-9357.5.2.068.

[6] R. Salgaonkar, "Chilled Cabbage Leaves: The Possible Remedy for Breast Engorgement," Int. J. Nurs. Med. Investig., vol. 4, no. 1, pp. 1-3, 2019, doi: 10.31690/ijnmi/30.

[7] S. Saleha, Asuhan Kebidanan pada Masa Nifas. Jakarta: Salemba Medika, 2009

[8] A.-R. Lim, J.-A. Song, M.-H. Hur, M.-K. Lee, and M. S. Lee, "Cabbage compression early breast care on breast engorgement in primiparous women after cesarean birth: a controlled clinical trial," Int. J. Clin. Exp. Med., vol. 8, no. 11, pp. 21335-21342, Nov. 2015, [Online]. Available: https://pubmed.ncbi.nlm.nih.gov/26885074.

[9] Y. Astuti and T. Anggarawati, "Pengaruh Kompres Kubis Terhadap Breast Engorgement Ibu Postpartum Sectio Caesarea," Indones. J. Nurs. Res. ..., 2019

[10] F. Rizki, The Miracle of Vegetables. Jakarta: Agro Media Pustaka, 2013.

[11] R. Sharma, "Effectiveness of Chilled Cabbage Leaf Application on Breast Engorgement among Post Partum Women's," J. Med. Sci. Clin. Res., vol. 6, no. 6, 2018, doi: 10.18535/jmscr/v6i6.147.

[12] K. L. Roberts, M. Reiter, and D. Schuster, "A Comparison of Chilled and Room Temperature Cabbage Leaves in Treating Breast Engorgement," J. Hum. Lact., 1995, doi: $10.1177 / 089033449501100319$

[13] A. Akanksha Thomas, "A Quasi-experimental Study to Assess the Effectiveness of Chilled Cabbage Leaves on Breast Engorgement among Postnatal Mothers Admitted in a Selected Hospital of Delhi," Int. J. Nurs. Midwifery Res., vol. 4, no. 1, pp. 8-13, 2017, doi: 10.24321/2455.9318.201702.

[14] B. B. Wong et al., "Application of cabbage leaves compared to gel packs for mothers with breast engorgement: Randomised controlled trial,” Int. J. Nurs. Stud., 2017, doi: 10.1016/j.ijnurstu.2017.08.014.

[15] B. Boi, S. KOH, and D. Gail, "The effectiveness of cabbage leaf application (treatment) on pain and hardness in breast engorgement and its effect on the duration of breastfeeding," JBI Evid. Synth., vol. 10 no. 20, 2012, [Online]. Available: https://journals.lww.com/jbisrir/Fulltext/2012/10200/The effectivene ss_of_cabbage_leaf_application.1.aspx. 